DOI: 10.20472/IAC.2018.043.035

\title{
OXANA POSUKHOVA
}

Southern Federal University, Russian Federation

LUDMILA KLIMENKO

Southern Federal University, Russian Federation

PAVLINA BALDOVSKAYA

Southern Federal University, Russian Federation

OXANA NOR-AREVYAN

Southern Federal University, Russian Federation

\section{LABOR PRECARIZATION: RUSSIAN EMPIRICAL EVIDENCE}

\begin{abstract}
:
In the conditions of educational and health institutions reforming and a series of economic crises, representatives of social-oriented helping professions move to the precarization zone. Based on the survey conducted in the spring of 2017 (2,054 school teachers and 870 physicians in state organizations in Moscow, Rostov-on-Don and Kazan), signs of precracious labor were identified: instability, the risk of job loss/changing, an increase in workload, not accompanied by higher wages, social and economic vulnerability. The empirical data shows that despite the satisfactory self-assessment of socially-oriented professionals' life, the level of precarious labor is higher for teachers from provincial cities and lower in the capital schools. In the field of health care, the extent of precarization is approximately the same in the different cities. Most teachers and doctors are concerned about the growth of workload without increasing wages and the risks of job loss. The majority of representatives of helping professions do not agree with the fact that the state effectively solves the social and economic problems of teaching. At the same time, interviewed teachers and doctors will take a rather passive attitude in case of violation of their labor rights. Nothing will be done by more than a half of all respondents. However, the excessive regulation of school teachers and physicians, on the one hand, and the continuing high demand for the work of schools and hospitals on the other, are associated with the risk of social tension increase in the Russian society.
\end{abstract}

\section{Keywords:}

labor precarization, helping professions, school teachers, physicians, instability, workload, vulnerability

JEL Classification: J28, J81, A13 


\section{Introduction}

A series of economic crises, a decline in the production, an increase in unemployment and instability of the labor market have led to an increase in the flexibility of social and labor relations in the Russian society. The wage payment system and working time arrangements are unsustainable, often violating the employee's labor rights. In the sphere of hiring and installment, the rules and procedures for dismissal, transfer to worse payment principles and working conditions are simplified. The deterioration of the social and labor situation of a large number of workers, the growth of their social vulnerability and instability in the labor market, the expansion of informal employment have been designated as the process of precarization in the academic literature.

Under the conditions of education and healthcare institutes reforming, as well as the passage of a series of economic crises, the situation of Russian teachers and physicians even does not improve, but worsens in many aspects. It is possible to distinguish the following signs of precarization of teachers' and physicians' labor: social and economic vulnerability, instability and risk of loss/change of work, growth of the workload without increase in wages, failure to respect the social and labor rights (Klimenko LV, Posukhova O.Yu. 2017a; 2017b). At the same time, the worsening socioeconomic situation, unnecessary overload labor and administrative burden, high social demands on the results of teachers' and doctors' work reduce the effectiveness of their work, lead to professional demotivation, weaken the potential of the education and health system reforms. Therefore, the purpose of this paper is to characterize the degree of labor precarization of helping professional groups (teachers, physicians) in Russian megacities on the basis of the applied research.

\section{Literature Review}

In Germany, about a fifth of all employees are involved in precarious work, and about a quarter of the able-bodied population - in France, Holland and Greece (Gasyukova 2015; Gialis, Tsampra 2015). Rise in uncertainty and risk are increasingly characterizing the American labor market (Kidder 2016). The processes of the employment structure deformation were manifested in Japan, South Korea, where $40 \%$ to $50 \%$ of economically employed people work on unstable employment conditions (Standing 2014; Pilling 2014). Under current conditions people with a relatively high level of education also have to be content with work that has a status or income below their qualifications (sign of the precarization processes). This phenomenon is widespread among young professionals in Japan (Kosugi R., Mouer R. 2008).

According to the Russian Longitudinal Monitoring Survey (RLMS), the average length of service was declining from 1994 to the crisis of 2008-2009 in Russia. In spite of the fact that the opposite tendency is emerging, it remains still much lower than in 1994. New 
forms of precarious employment also often involve impairment of the social and labor rights: outsourcing and outstaffing, staff leasing, hiring of temporary staff. But not all of them contribute to the rational use of working hours and the development of an innovative economy (Bazhina et al. 2004). The number of precarious groups, therefore, is constantly growing, including people, who have permanent employment for a moment and are often classified as a middle class (Toshchenko Zh. T. 2015). Under the crisis of 2015 a sharp expansion of the poor group and a general depletion of Russians also led to the replenishment of precariat (Slobodenyuk E. 2015).

In academic literature the problem of precarization is considered in connection with a low assessment of the profession's social status (Fuller C. 2013), educational reforms that increase the workload (Cheung ACK, Man Wong P. 2012) and adversely affect the professional identity of teachers (Hall D., McGinity R. 2015). Specialists note that the new monitoring, inspection and public reporting systems directly related to the performance rating, in addition to the increased bureaucratic burden, lead to a growth of the level of uncertainty, instability and vulnerability of teachers as a result of these reforms (Ball S. J. 2003). Under education system reforms teachers are jammed, on the one hand, by the requirements of the administration, and, on the other, by the resistance of students (Yan C. 2012).

Similar problems of medical work are recorded in a number of foreign countries. Low incomes, overload labor, general dissatisfaction are aspects of Chinese physicians' work (Wu D. Wang Y. et al., 2014). Their European counterparts suffer to a lesser extent - only the young doctors are at risk of falling into the precariat zone (lliffe S. 2017). In the United States, the need for reform was primarily aroused from the inaccessibility of health care for the general public and the disintegration in health services provision. The main point for criticism from American physicians remains the decline in their autonomy (Emanuel E. J., Pearson S.D. 2012).

\section{Teachers' and Physicians' Labor Precarization Assessment}

The applied sociological research was conducted in three Russian megacities - Moscow, Rostov-on-Don and Kazan, - among representatives of helping professionals (school teachers, physicians from state-financed institutions) in the spring of 2017.

The sample of the mass opinion poll is quota-proportional, the statistical error of the survey does not exceed $4-5 \%$. A total of 2,054 school teachers and 870 doctors from three cities filled self-completed questionnaires.

Empirical evidence suggests that social-oriented professional labor precarization levels in province and the capital are different.

From $36 \%$ to $46 \%$ of Moscow tutors experience workload increase compared to $64 \%-$ $76 \%$ in Rostov-on-Don and 65\%-81\% in Kazan. Furthermore, the majority of Moscow and Kazan teachers claim that class preparation and off-hour work are taking more and 
more of their time, while Rostov-on-Don specialists are rather concerned about the growing amount of desk-work and unnecessary reporting (Fig. 1).

Figure 1: How has your workload changed over the past 1-2 years? Teachers, single choice, \%

class preparation $\square$ desk-work and reporting $\square$ individual work with students $\$$ off-hour work

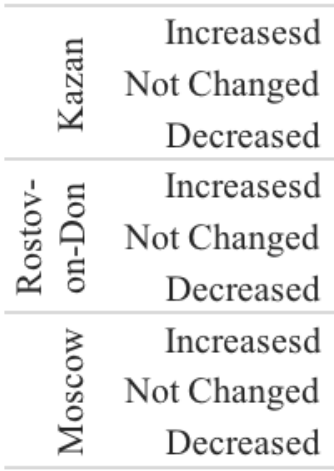

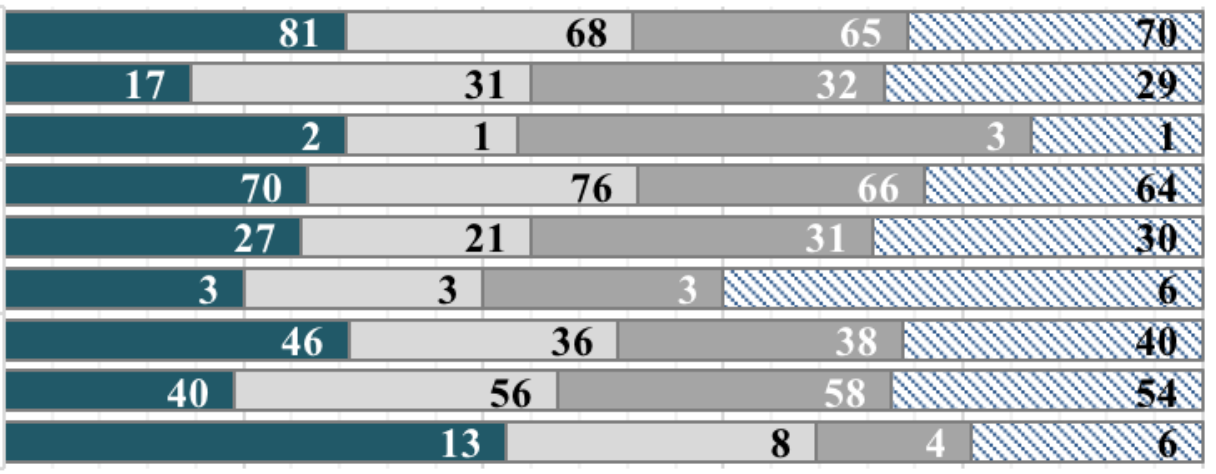

Source: Authors.

Medical staff polls unravel rising workload levels in Moscow and Kazan within the last 1-2 years with job responsibilities to surge by $80 \%$ and $67 \%$ respectively. Increasing deskwork is reported by physicians from Moscow (57\%) and Kazan (78\%). Additionally, workload increase unrelated to job responsibilities is observed by $66 \%$ of Moscow physicians compared to only $46 \%$ in Kazan (Fig. 2). 
Figure 2: How has your workload changed over the past 1-2 years? Physicians, single choice,

$\%$

Ejob responsibilities, scope of tasks $\square$ desk-work and reporting $\square$ non-executive activities

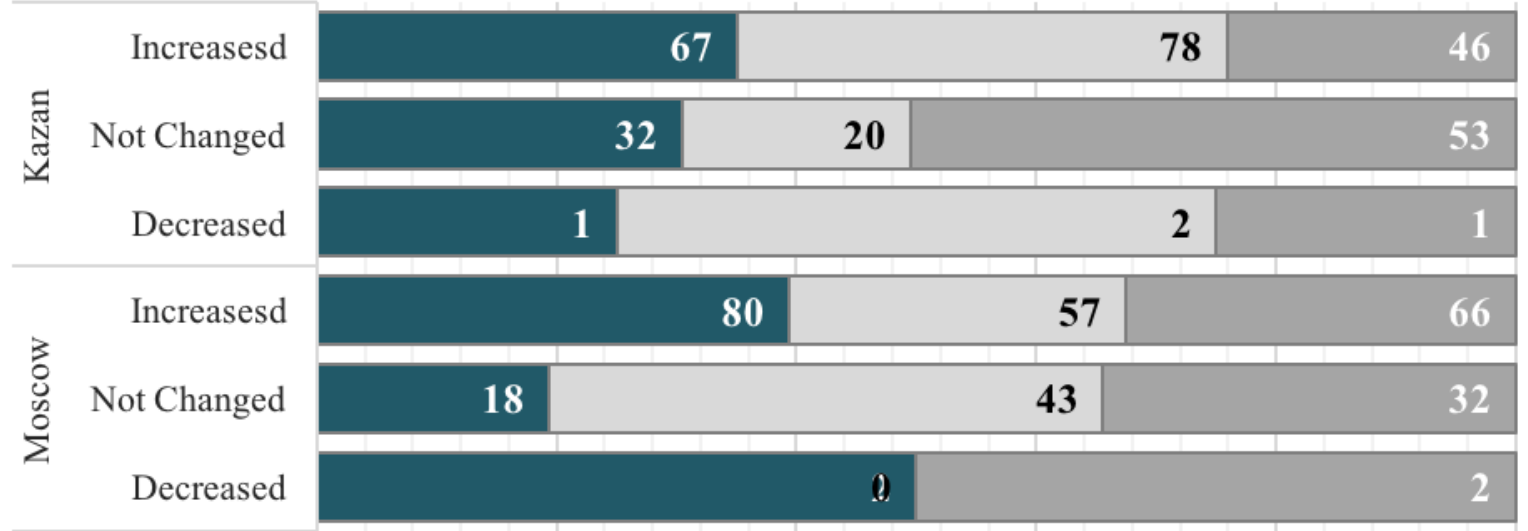

Source: Authors.

In our study, social oriented specialists were also asked if they are concerned about precarization effects.

The results demonstrated that school teachers are worried about the risks of workload increase without a pay raise (Moscow - 71\%, Rostov-on-Don - 84\%, Kazan - 73\%), a job loss (Moscow - 78\%, Rostov-on-Don - 62\%, Kazan - 49\%), salary reduction or delay (Moscow - 58\%, Rostov-on-Don - 48\%, Kazan - 41\%), and involuntary transition to underemployment (Moscow - 55\%, Rostov-on-Don - 41\%, Kazan - 35\%) (Table 1).

Table 1: Distribution of respondents' answers to the question "How much do you currently worry about the following professional risks?" Teachers, single choice, $\%$

\begin{tabular}{|c|c|c|c|c|c|c|c|c|c|c|c|c|}
\hline \multirow[b]{2}{*}{ Professional Risks } & \multicolumn{4}{|c|}{ Moscow } & \multicolumn{4}{|c|}{ Rostov-on-Don } & \multicolumn{4}{|c|}{ Kazan } \\
\hline & 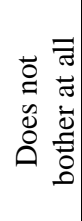 & 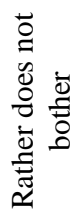 & 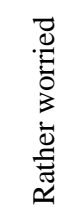 & 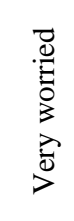 & 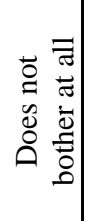 & 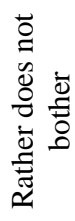 & 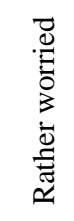 & 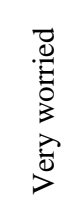 & 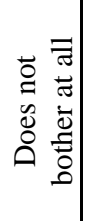 & 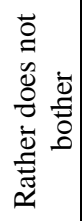 & 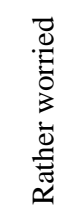 & 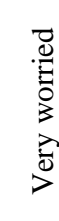 \\
\hline salary reduction or delay & 24 & 18 & 36 & 22 & 24 & 27 & 29 & 19 & 30 & 28 & 23 & 18 \\
\hline $\begin{array}{l}\text { involuntary transition to } \\
\text { underemployment }\end{array}$ & 15 & 30 & 31 & 24 & 32 & 27 & 26 & 15 & 33 & 33 & 20 & 15 \\
\hline $\begin{array}{l}\text { growth of workload without } \\
\text { increase in wages }\end{array}$ & 9 & 20 & 36 & 35 & 4 & 13 & 34 & 50 & 12 & 15 & 34 & 39 \\
\hline job loss & 6 & 15 & 25 & 53 & 15 & 23 & 25 & 37 & 22 & 29 & 18 & 31 \\
\hline
\end{tabular}

Source: Authors. 
Precarization induced risks are more of a threat for Moscow physicians than those living and working in Kazan, and also tutors in general. The overwhelming majority of the interviewed physicians working for a publicly funded medical institution in Moscow and Kazan are worried about workload increase without a pay raise (Moscow - 95\%, Kazan $63 \%$ ), a job loss (Moscow $-89 \%$, Kazan $-57 \%$ ), salary reduction or delay (Moscow $89 \%$, Kazan $-43 \%$ ), and involuntary transition to underemployment (Moscow $-75 \%$, Kazan - 30\%) (Table 2).

Table 2: Distribution of respondents' answers to the question "How much do you currently worry about the following professional risks?" Physicians, single choice, \%

\begin{tabular}{|c|c|c|c|c|c|c|c|c|}
\hline \multirow[b]{2}{*}{ Professional Risks } & \multicolumn{4}{|c|}{ Moscow } & \multicolumn{4}{|c|}{ Kazan } \\
\hline & 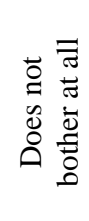 & 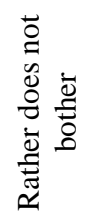 & 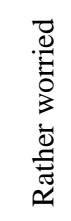 & 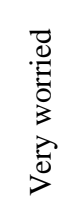 & 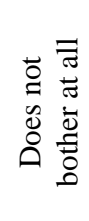 & 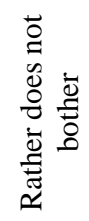 & 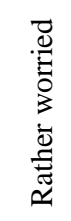 & 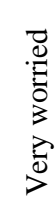 \\
\hline salary reduction or delay & 3 & 9 & 32 & 57 & 27 & 31 & 22 & 21 \\
\hline $\begin{array}{l}\text { involuntary transition to } \\
\text { underemployment }\end{array}$ & 7 & 17 & 38 & 37 & 31 & 40 & 20 & 10 \\
\hline $\begin{array}{l}\text { growth of workload without } \\
\text { increase in wages }\end{array}$ & 1 & 4 & 41 & 54 & 19 & 18 & 34 & 29 \\
\hline job loss & 3 & 7 & 32 & 57 & 20 & 24 & 34 & 23 \\
\hline
\end{tabular}

Source: Authors.

\section{Conclusion}

Health care and educational sector reforms aimed to improve the quality of services turn into desk-work overload, unnecessary reporting responsibilities, new formalized operational standards adoption that leads to teachers and doctors unable to do their job of teaching or curing people. The study provides empirical evidence of lower tutors' labor precarization level in the capital compared to province, and almost identical doctors' labor precarization levels. Tutors and physicians are mostly worried about the risks of workload increase without a pay raise.

Health care and educational sector reforms often result in doctors and teachers loosing reliable guarantees of employment. Constantly upgrading standards ask a lot of social oriented specialists who are unsuitable for desk-work or just lacking technical abilities, that eventually leads to natural push-back on innovation. On top of that, workload increase frequently comes without any pay raise at all, which, coupled with inflation, may end in the disposable real income being decreased. Immoderate teachers' and doctors' activity regulation on the one hand, and high expectations people put on schools and hospitals on the other, create political tension in the Russian society. As a result, these 
problems discourage teachers and physicians from being professional, and bring public sector down to stagnation.

\section{Acknowledgements}

The paper was prepared with the support of the Russian Science Foundation, project No. 16-18-10306.

\section{Reference}

Gasukova, E. N., 2015. Precarization: conceptual grounds, factors and estimates. Contours of global transformations: politics, economics, law, 8 (6 (44)).

Klimenko, L. V. and Posukhova, O. Yu., 2017. Gender aspects of labor precariation in Russian society. A woman in Russian society, (1 (82)).

Klimenko, L. V. and Posukhova, O. Yu., 2017. Professional identity of city teachers in the conditions of modernization of the institute of education. Journal of Institutional Studies, 9(2).

Slobodenyuk, E. D., 2017. Consequences of the 2015 crisis: impoverishment or precarization ?. Journal of Social Policy Studies, 15(2).

Toshchenko, Zh. T., 2015. Prekaryat is a new social class. Sociological research, (6), pp. 3-13.

Bazhina, V. A., Tsygankova, I. V. and Nikishina, O. Yu., 2014. Development of non-standard forms of employment in modern Russia. Russian entrepreneurship, (24 (270)).

Ball, S. J., 2003. The teacher's soul and the terrors of performativity. Journal of education policy, 18(2), pp. 215-228.

Cheung, A. C. and Man Wong, P., 2012. Factors affecting the implementation of curriculum reform in Hong Kong: Key findings from a large-scale survey study. International Journal of Educational Management, 26(1), pp. 39-54.

Emanuel, E. J. and Pearson, S. D., 2012. Physician autonomy and health care reform. Jama, 307(4), pp. 367-368.

Fuller, C., Goodwyn, A. and Francis-Brophy, E., 2013. Advanced skills teachers: professional identity and status. Teachers and Teaching, 19(4), pp. 463-474.

Gialis, S. and Tsampra, M., 2015. The diverse regional patterns of atypical employment in Greece: Production restructuring, re/deregulation and flexicurity under crisis. Geoforum, 62, pp. 175-187.

Hall, D. and McGinity, R., 2015. Conceptualizing teacher professional identity in neoliberal times: Resistance, compliance and reform. Education Policy Analysis Archives/Archivos Analíticos de Políticas Educativas, 23, pp. 88.

lliffe, S., 2017. A tale of three disputes: junior doctors against the government 20152016. Soundings, 64(64), pp. 128-142.

Kidder, J. L., 2016. Hollywood, bike messengers, and the new economy. Critical Sociology, 42(2), pp. 307322. 
Kosugi, R., and Mouer, R., 2008. Escape from work: Freelancing youth and the challenge to corporate Japan. Trans Pacific Pr.

Wu, D., Wang, Y., Lam, K. F. and Hesketh, T., 2014. Health system reforms, violence against doctors and job satisfaction in the medical profession: a cross-sectional survey in Zhejiang Province, Eastern China. BMJ open, 4(12).

Yan, C., 2012. 'We can only change in a small way': A study of secondary English teachers' implementation of curriculum reform in China. Journal of Educational Change, 13(4), pp. 431-447. 